\title{
Efficacy of phosphorus-32 brachytherapy without external-beam radiation for long-term tumor control in patients with craniopharyngioma
}

\author{
Shaheryar F. Ansari, MD, ${ }^{1}$ Reilin J. Moore, BS, ${ }^{1}$ Joel C. Boaz, MD, ${ }^{2}$ and Daniel H. Fulkerson, MD² \\ 1'Department of Neurological Surgery and 2Division of Pediatric Neurosurgery, Indiana University School of Medicine, Goodman \\ Campbell Brain and Spine, Indianapolis, Indiana
}

\begin{abstract}
OBJECTIVE Radioactive phosphorus-32 (P32) has been used as brachytherapy for craniopharyngiomas with the hope of providing local control of enlarging tumor cysts. Brachytherapy has commonly been used as an adjunct to the standard treatment of surgery and external-beam radiation (EBR). Historically, multimodal treatment, including EBR, has shown tumor control rates as high as $70 \%$ at 10 years after treatment. However, EBR is associated with significant longterm risks, including visual deficits, endocrine dysfunction, and cognitive decline. Theoretically, brachytherapy may provide focused local radiation that controls or shrinks a symptomatic cyst without exposing the patient to the risks of EBR. For this study, the authors reviewed their experiences with craniopharyngioma patients treated with P32 brachytherapy as the primary treatment without EBR. The authors reviewed these patients' records to evaluate whether this strategy effectively controls tumor growth, thus avoiding the need for further surgery or EBR.
\end{abstract}

METHODS The authors performed a retrospective review of pediatric patients treated for craniopharyngioma between 1997 and 2004. This was the time period during which the authors' institution had a relatively high use of P32 for treatment of cystic craniopharyngioma. All patients who had surgery and injection of P32 without EBR were identified. The patient records were analyzed for complications, cyst control, need for further surgery, and need for future EBR.

RESULTS Thirty-eight patients were treated for craniopharyngioma during the study period. Nine patients (23.7\%) were identified who had surgery (resection or biopsy) with P32 brachytherapy but without initial EBR. These 9 patients represented the study group. For 1 patient (11.1\%), there was a complication with the brachytherapy procedure. Five patients $(55.5 \%)$ required subsequent surgery. Seven patients $(77.7 \%)$ required subsequent EBR for tumor growth. The mean time between the injection of P32 and subsequent treatment was $1.67 \pm 1.50$ years (mean \pm SD).

CONCLUSIONS In this small but focused population, P32 treatment provided limited local control for cyst growth. Brachytherapy alone did not reliably avert the need for subsequent surgery or EBR.

http://thejns.org/doi/abs/10.3171/2015.8.PEDS15317

KEY WORDS brachytherapy; craniopharyngioma; phosphorus-32; pediatric; outcome; oncology

$\mathrm{C}$ RANIOPHARYNGIOMAS present a therapeutic challenge to neurosurgeons. Although these tumors are surrounding brain. This creates substantial difficulty for complete removal, with high risks of morbidity and recurrence..$^{15,31}$ Despite the daunting challenge, survival for these patients has improved over the years. ${ }^{8}$ Morbidity risk remains high, with endocrine deficiencies in as many as $85 \%$ of patients, visual compromise in up to $63 \%$ of patients, and cognitive deficits in up to $40 \% .^{9,10,14,15}$ Morbidity risk comes not only from direct effects of the tumor, but also from adverse effects of treatment.
The treatment approach has ranged over the years from aggressive resection ${ }^{9}$ to mere biopsy with radiation. ${ }^{6}$ Currently, most surgeons prefer a balanced approach that involves conservative resection with postoperative radiation. ${ }^{16,25,29-31}$ This balanced approach has yielded satisfactory outcomes, with local tumor control rates greater than $75 \% .{ }^{14}$ Advanced surgical and radiation techniques have reduced the risks of endocrine and visual complications. ${ }^{10,16,25}$ However, both surgery and radiation carry inherent risks. External-beam radiation (EBR), in particular, carries risks of cognitive decline, vision impairment, and endocrine dysfunction. ${ }^{2,17,27,28}$

ABBREVIATIONS EBR = external-beam radiation; $\mathrm{MCA}$ = middle cerebral artery; P32 = phosphorus-32 
More than $90 \%$ of craniopharyngiomas have a cystic component; approximately half are predominantly or purely cystic. ${ }^{17,28}$ The cyst itself may cause clinical symptoms from local mass effect. Intracystic brachytherapy may provide local control of the cyst by direct injection of a radioactive agent (a $\beta$-emitter; in the US, the agent used is primarily phosphorus-32 [P32]), thus applying focused, local radiation. ${ }^{17}$ This concept was first described by Leksell and Liden in $1952 .{ }^{19}$ Ideally, brachytherapy will control the tumor without exposing the patient to the risks of external radiation. Numerous studies have been published on its techniques, indications, and efficacy. $4,5,7,11,12,17,21,26-28$ In most studies, brachytherapy is combined with EBR. Previously, we attempted to treat predominantly cystic craniopharyngiomas with brachytherapy alone, withholding external radiation. In this study, we examined the records of patients who were treated in this manner to analyze whether brachytherapy alone prevented the need for subsequent external radiation therapy.

\section{Methods}

The study began after approval by the Indiana University institutional review board. A retrospective review was performed of the records of patients treated for cystic craniopharyngioma at Riley Hospital for Children (Indianapolis, IN) between 1997 and 2004. This study period was chosen because this was the time when P32 brachytherapy was used as a primary treatment at our institution. Patients who had undergone surgery (biopsy or resection) with P32 instillation but without initial EBR were identified. Data points included age at diagnosis, sex, treatment (surgical procedures, radiation therapy), date of last follow-up, preoperative symptoms, postoperative complications, number of P32 injections, complications from P32, evidence of cystic recurrence or tumor progression, and the initial extent of resection. These patient records were analyzed to determine if P32 brachytherapy prevented the need for further surgical or EBR therapy. Failure of therapy was defined as radiographic increase in size of the cyst or lack of shrinkage as shown on serial imaging. Local control was defined as shrinkage of the cyst as shown on serial imaging. Extent of resection was defined as complete if postoperative MRI showed no enhancing areas, and partial if enhancement or calcification remained on the postoperative scan.

\section{Surgical Technique}

Treatment strategies were individualized based on the patient's age, presentation, clinical findings, and anatomy of the tumor. During the study period, we were fairly conservative with surgery, with the goal of gross-total resection. At the time, we also were conservative with EBR for fear of the long-term effects. Patients were selected for P32 brachytherapy if their tumor had a large cystic component but was unlikely to be resectable without significant morbidity to the patient. Patients who had a tumor with a large solid component were also treated with EBR. Patients with a primarily cystic tumor with a small solid component were treated with brachytherapy alone.

Nine patients were identified who were treated with brachytherapy without EBR. Two techniques were used to instill P32 into the tumor cyst. ${ }^{4}$ The method chosen was individualized by the treating surgeon for each particular patient. In 7 of the 9 patients, a cyst puncture catheter was stereotactically inserted into the cyst and connected to a subcutaneous reservoir for the dual purpose of periodic drainage of cyst fluid and instillation of the radioactive agent. In these patients, the radioactive agent was instilled through the reservoir after a volume of cyst fluid equal to the volume of P32 solution was removed. In cases where the cyst itself was symptomatic, approximately $30 \%$ more cyst fluid was removed. Radioactive materials were acquired through the radiation safety officer at Indiana University School of Medicine. Bremsstrahlung scans were obtained 1 week after injection. This scan is essentially a single image taken with a radiation camera that assesses for leakage of radioactive material from the original injection location. In the remaining 2 patients, the radioactive material was injected directly using stereotactic guidance to access the cyst with a needle. In both these cases, after the radioactive compound was injected, barbotage was used to adequately mix the agent with cyst fluid. The radiation dosage was calculated to be approximately 300 Gy to the cyst wall.

\section{Results}

Thirty-eight patients were treated for craniopharyngioma during the study period. Thirteen of these patients underwent injection of $\mathrm{P} 32$. Four of the 13 patients had prior or concurrent EBR treatment. The other 9 patients underwent surgery followed by brachytherapy without EBR. Demographic data of these 9 patients, including age at diagnosis, presenting symptoms, extent of resection, number of P32 injections, as well as complications from surgery or instillation of P32, are presented in Table 1. There were 6 boys and 3 girls ranging in age from 3 to 15 years. For 2 of the 9 patients $(22.2 \%)$, control of the cyst was obtained with only P32 instillation and no EBR at a mean \pm SD of $3.5 \pm 3.5$ years. Seven patients $(77.7 \%)$ required EBR subsequently for tumor growth at a mean of $22.2 \pm 17.8$ months. Five patients (55.5\%) required subsequent surgery (cyst fenestration or shunting) for tumor progression at a mean of $1.67 \pm 1.50$ years. The mean length of follow-up for the whole population was $6.7 \pm 3.5$ years. Seven of the 9 patients (77.7\%) had progression or recurrence of solid portions of their tumor. One patient died as a result of her tumor 12 years after diagnosis.

There was no relationship detected between the number of P32 injections and complications related to the injections. Radioactivity scans in all cases showed confinement of radioactivity to the cyst contents. For 1 patient (11.1\%), there was a complication (hyponatremia) with P32 instillation, which may have been related to irritation of the pituitary gland. One patient in our series had a middle cerebral artery (MCA) stroke on the right side, which was not attributed to the instillation of P32. No patients with intact vision preoperatively had worsened vision postoperatively. Five of the 9 patients (55.5\%) had diabetes insipidus following surgery. All patients had adamantinomatous histological subtypes. There were no clear differences in the demographic characteristics of the 2 patients who had 


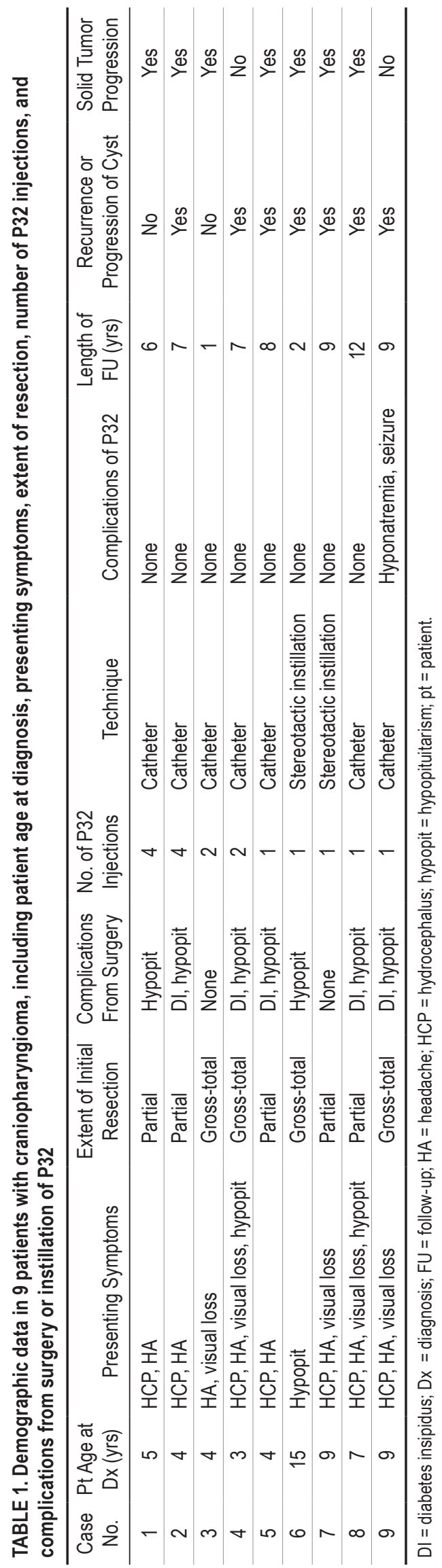

cyst control compared with the 7 who did not. One patient (Case 1) had an initial partial resection, and the other (Case 3) had an initial gross total resection.

Among patients who underwent primary P32 therapy, $77.7 \%$ ( 7 of 9) had solid tumor recurrence or growth. Conversely, patients who did not have P32 as primary therapy had a solid tumor recurrence rate of $28.6 \%$.

\section{Illustrative Case \\ Case 4}

A 3-year-old boy presented with worsening headaches and clumsiness. These headaches woke the child from sleep. He was not having any nausea, vomiting, or fevers. He did not have any issues with urination or thirst. He had a normal height and weight for his age. Ophthalmological evaluation showed mild papilledema, but formal visual field evaluation was limited by the child's lack of cooperation. Endocrinological work-up showed mild prolactin elevation with a slightly low level of thyroid-stimulating hormone. His physical examination was otherwise unremarkable.

Preoperative MRI (Fig. 1 upper) showed a predominantly cystic lesion with enhancing borders, as well as evidence of hydrocephalus and transependymal flow (Fig. 1 lower). The child initially underwent a bicoronal craniotomy for gross-total resection with fenestration of the septum pellucidum (Fig. 2). Postoperatively, he had left arm and leg weakness, which improved with rehabilitation. He did not undergo ventricular shunting at the time. He required treatment with thyroxine and growth hormone. $\mathrm{He}$ did not undergo radiation therapy.

Just over 1 year later, the patient presented with worsening headaches and vision, as well as concerns about hydrocephalus based on imaging. He had a ventriculoperitoneal shunt placed at that time. Detailed imaging obtained after the shunt placement showed recurrence of the tumor with a multilobulated cystic component (Fig. 3). He then underwent stereotactic instillation of P32, according to the technique outlined above. He tolerated this procedure well and was discharged to home. On the initial follow-up imaging 3 months later, the cysts were slightly decreased in size (Fig. 4). At that time, it was decided to follow the patient clinically and radiographically. Upon follow-up imaging 6 months after his initial P32 treatment, the patient returned once again with worsened vision and headaches (Fig. 5). At this time, he underwent placement of a catheter and subcutaneous reservoir to aspirate cyst fluid. More P32 was injected after 4 weeks, to give the cyst time to seal around the catheter. The patient was followed up for 1 year after the second instillation and was again noted to have an increase in cyst size (Fig. 6). At this point, he underwent proton beam radiotherapy. The patient has not required any further surgical or radiation treatment in the 7 years of subsequent follow-up. He does have diabetes insipidus, panhypopituitarism, hypothalamic obesity, and hemiparesis. He attends school at the appropriate grade level.

\section{Discussion}

The technique of instillation of a radioactive compound 

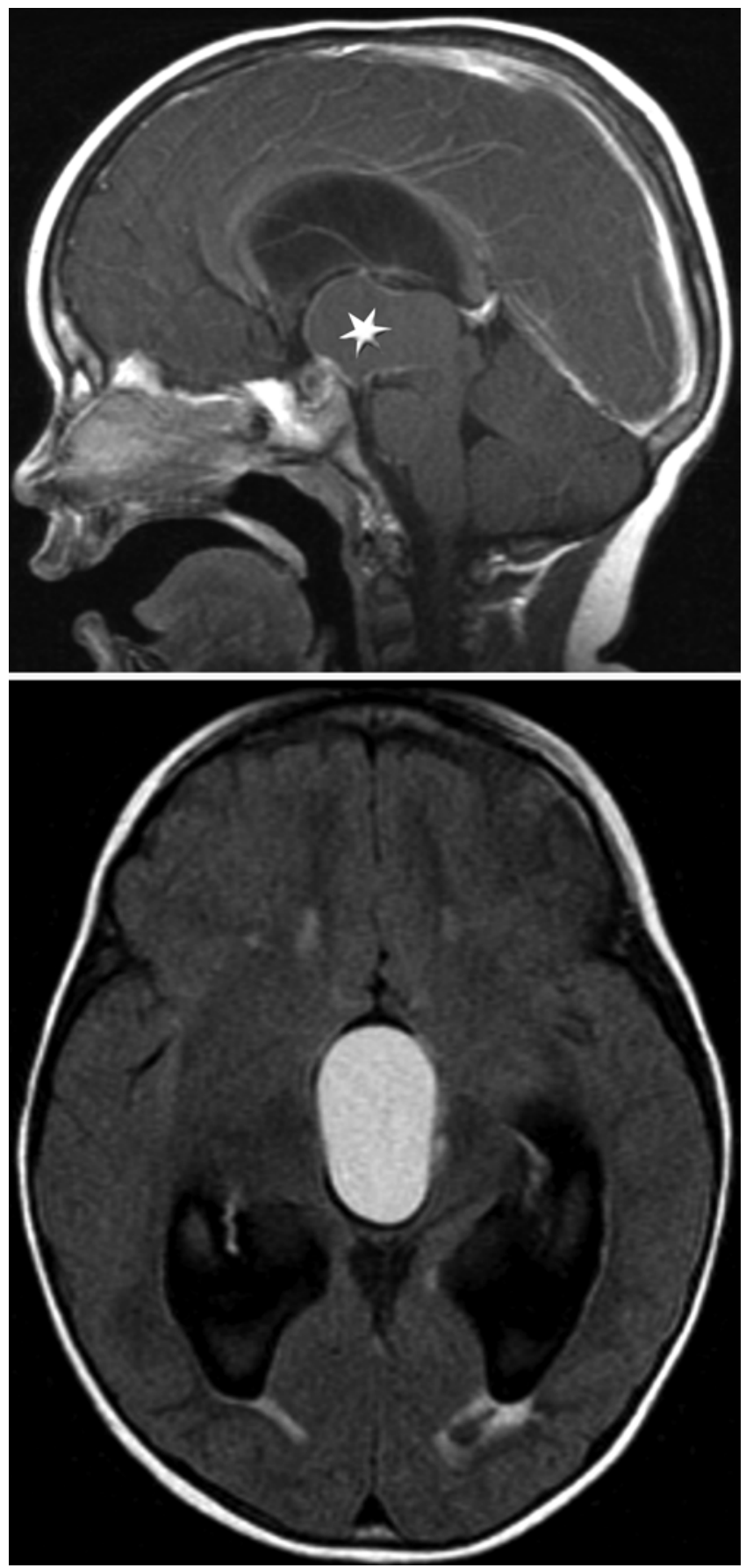

FIG. 1. Upper: Preoperative sagittal contrast-enhanced T1-weighted MR image shows a predominantly cystic suprasellar tumor (star). Lower: Axial FLAIR image shows the cystic tumor with ventricular enlargement and transependymal flow.

to treat cystic craniopharyngiomas was first described by Leksell and Liden in 1952..$^{19}$ A number of studies have assessed this modality since then., $4,5,711,17,21,22,27,28$ By and large, these studies have shown good cyst control with 1 or more instillations of P32 or yttrium-90. Almost all of these studies (including one from our institution) included patients who underwent multiple modalities of therapy, including varying degrees of resection and EBR. There re-

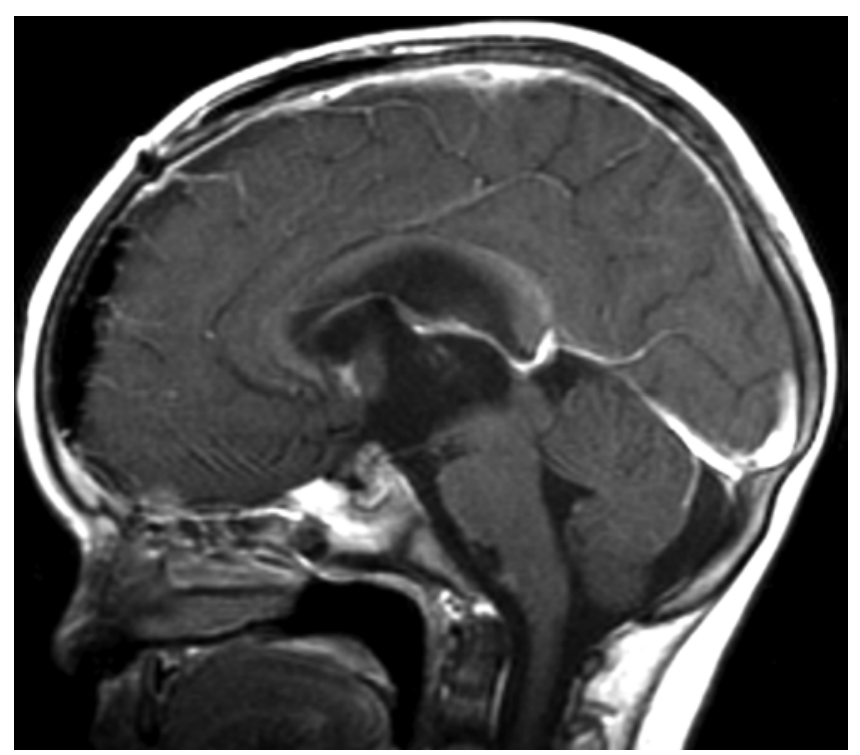

FIG. 2. Postoperative sagittal contrast-enhanced T1-weighted MR image shows a radiographic gross total resection of cyst with fenestration of the septum pellucidum.

mains no ideal therapy for craniopharyngioma and many patients require multimodal therapy. Currently, the consensus strategy includes maximal safe resection (i.e., without harming endocrine and visual structures) with radiation of any remnants. ${ }^{16}$ In the present study, we focused on a small group of pediatric patients with primarily cystic craniopharyngioma treated with intracystic P32 who did not undergo concurrent EBR therapy.

The efficacy of brachytherapy has been extensively discussed in a number of small, retrospective studies. Julow et al. ${ }^{11}$ showed shrinkage of the cyst from a mean volume of $10.6 \mathrm{ml}$ to $1.0 \mathrm{ml}$ in 60 patients who underwent instillation of yttrium-90. These authors noted that the patients did not have any changes in neurological symptoms, which they attributed to solid tumor components. Interestingly,

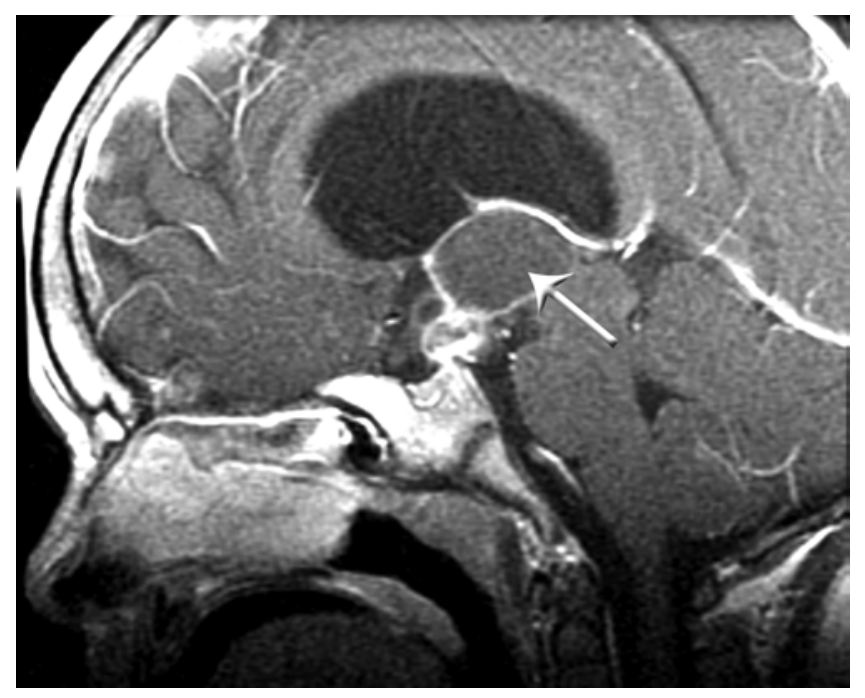

FIG. 3. Sagittal contrast-enhanced T1-weighted MR image shows a multilobulated cystic recurrence (arrow). 


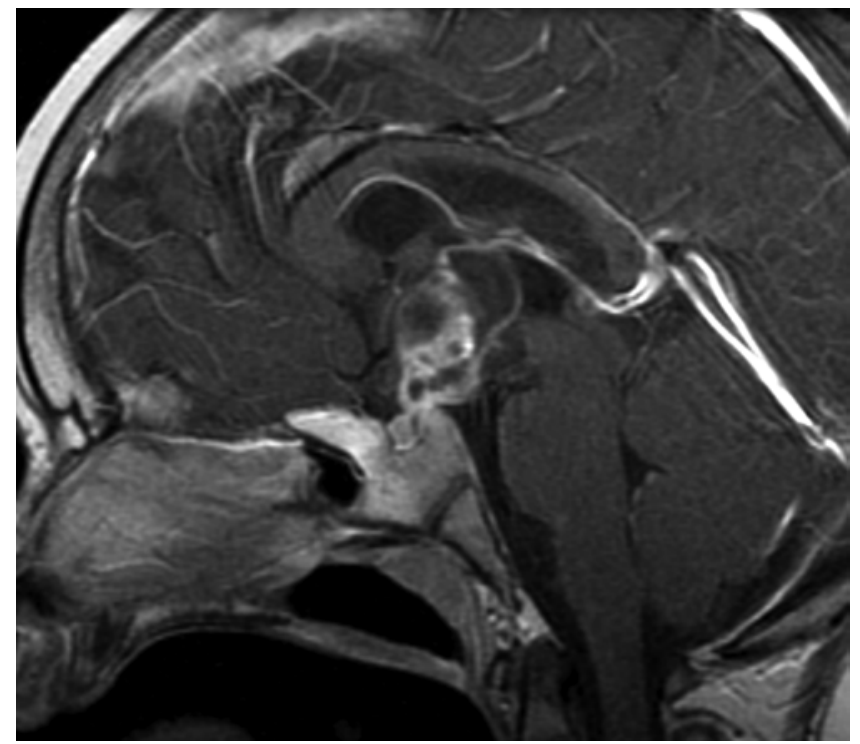

FIG. 4. Sagittal contrast-enhanced T1-weighted MR image obtained after P32 treatment shows a slight decrease in cyst size.

none of the patients in the study by Julow et al. had undergone EBR, similar to our own study. Similarly, Voges et al. ${ }^{28}$ showed complete shrinkage in almost $50 \%$ of their study population of 68 patients, with partial shrinkage in approximately one-third, also with yttrium-90. This group also demonstrated improvement in visual function after instillation. Patients in this study did undergo EBR therapy prior to or concomitant with intracystic therapy. Pollack et al. ${ }^{21}$ published an early experience with P32 instillation in 9 patients. Their study showed significant reduction in cyst size on follow-up imaging in all patients. Similar to others, this study showed that solid tumor progression continued despite cyst regression. Their study showed improvement in visual function in 4 of the 9 patients at follow-up. These authors did include patients who had undergone EBR. Van den Berge et al. ${ }^{27}$ showed cyst regression in most of their

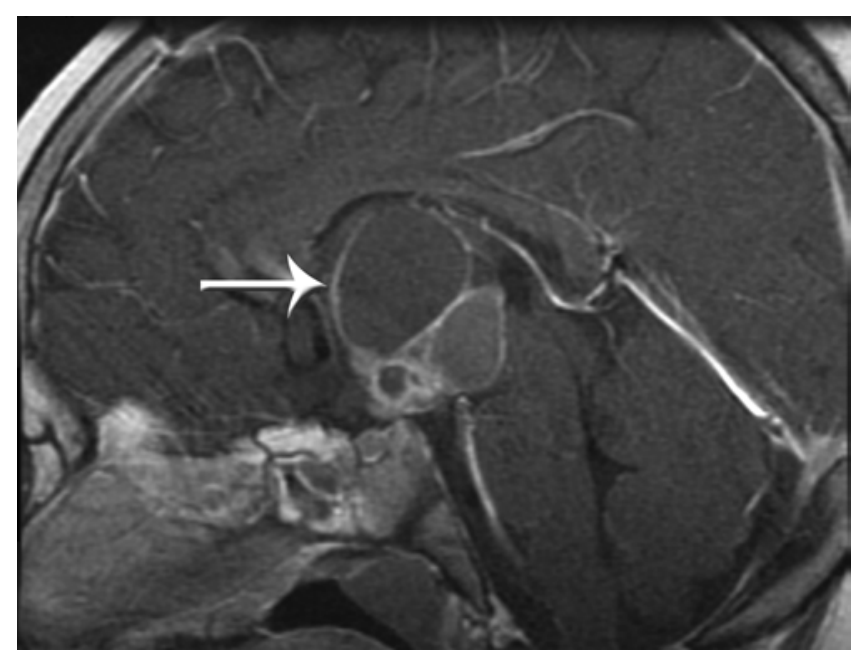

FIG. 5. Repeat sagittal contrast-enhanced T1-weighted MR image obtained 6 months after P32 treatment shows a significantly increased cyst size (arrow).

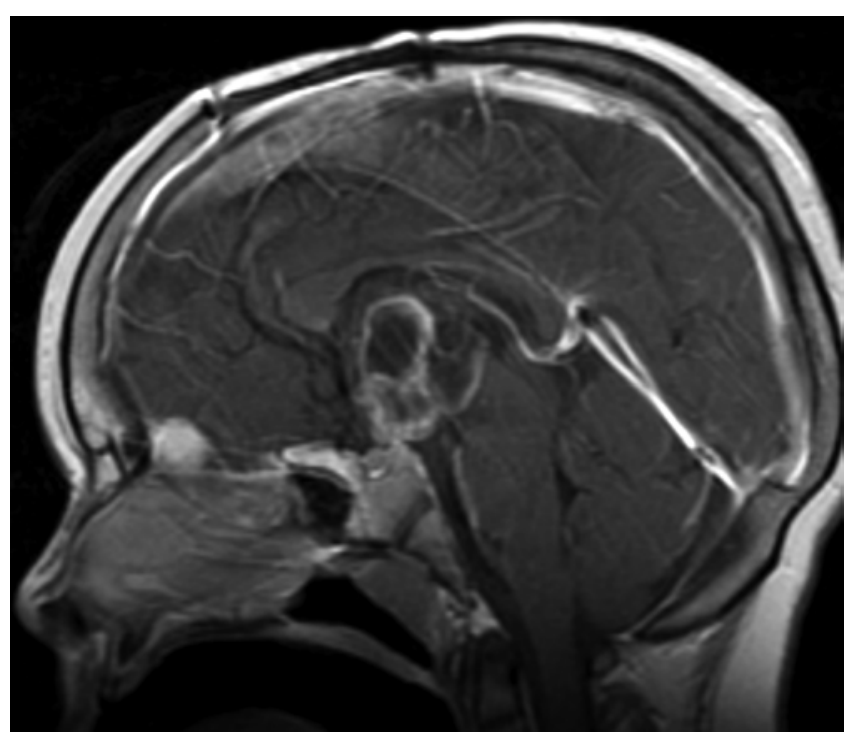

FIG. 6. Follow-up sagittal contrast-enhanced T1-weighted MR image obtained 3 months after a second P32 injection shows a stable to slightly larger cyst.

31 patients, with clear recurrence of cysts in 3 of them. Notably, visual acuity improved in 11 of 31 patients who had decreased vision preinstillation. ${ }^{27}$ All of these studies included a wide range of both adult and pediatric patients. A study from our own institution showed a $42 \%$ cyst control rate with P32 instillation. ${ }^{4}$ This study included patients who underwent prior or concurrent EBR. In the present study, we focused on the 9 patients who underwent P32 brachytherapy alone without EBR. In our experience, patients with EBR had improved tumor control rates, suggesting that this therapy is more efficacious than brachytherapy alone.

Complications from instillation of radioactive compounds into tumor cysts have been reported. In our series, 1 patient developed hyponatremia and resultant seizures after the treatment. One patient suffered an MCA stroke, which was not attributed to the treatment. Other authors have reported complications including cranial nerve palsies, ${ }^{2}$ worsened vision, $, 7,27,28$ and endocrine dysfunction. ${ }^{2,17}$ Leakage of radioactive material from the cyst has also been reported. ${ }^{3,28}$ Fortunately, no patient in our series experienced leakage of radioactive material. This is certainly a dreaded complication due to the potential for subarachnoid distribution of radioactive material, with a risk of tissue damage and vascular injury. All studies published used techniques to follow the placement of radioactive material and reassess this placement at some point after the procedure itself., $4,5,711,17,21,22,27,28$ Kickingereder et al. suggested injecting a benign radiotracer to determine security of the cyst walls prior to injection of the actual radioactive agent. ${ }^{17}$

Craniopharyngioma remains a challenge to treat despite advances in technology, surgical technique, and expertise. Over the last 50 years, the pendulum of optimal therapy has swung from aggressive resection ${ }^{9,30}$ to more conservative treatments (e.g., biopsy, shunting) combined with radiation, ${ }^{6,18,30}$ and it has now settled somewhere in 
between. Treatment should be tailored to the patient's clinical status and individual tumor anatomy to achieve the best outcome. ${ }^{2,31}$ Intuitively, it makes sense to the surgeon to remove as much tumor as possible, while saving critical structures to preserve vision and endocrine function. However, this drive must be countered by the potential risks associated with overly aggressive resection, such as devastating endocrine dysfunction or neurological deficits.

External-beam radiation carries the risks of alopecia and skin erythema, as well as visual deficits, hydrocephalus, and global cognitive deficits. Longer term, children may also develop optic neuropathy, endocrine disturbances, language and cognitive problems, and, rarely, secondary malignancies and radiation-induced vasculitis. ${ }^{13}$ Optic neuropathy is a dose-limiting complication, because the tolerance for radiation exposure at the optic chiasm is estimated to be approximately 12 Gy before the risk of optic neuropathy rises significantly. ${ }^{24}$ In young children, cognitive problems may persist for years after treatment. ${ }^{1,23}$ The incidence of secondary malignancy may be as high as $4 \%$ and may also persist for several years after radiation..$^{20}$ The goal of brachytherapy is to apply local radiation to a restricted area without passing through critical brain structures. Brachytherapy is primarily applied to patients who have tumors with large cystic components.

It was hoped that brachytherapy with P32 alone would control cyst growth without concurrent EBR. However, in our series, 7 of 9 patients (77.7\%) showed tumor progression sufficient to merit further radiation treatment within a mean of $22.2 \pm 17.8$ months. Five patients $(55.5 \%)$ required further surgery. Therefore, although brachytherapy may be part of a multimodal approach, our data did not support it as a stand-alone therapy for craniopharyngioma cysts. Within our institution, there has been a shift away from brachytherapy because trends in the literature suggested that a combination of surgery and EBR was more efficacious based on a patient's individual tumor. ${ }^{16,25,29-31}$ Similar to prior studies, we also found that P32 did not control solid tumors. ${ }^{11,31}$

\section{Limitations of the Study}

Our study is limited primarily by its small size and retrospective nature. Furthermore, no information was collected on quality of life or overall functional status at last follow-up. This is important information because many patients with craniopharyngioma suffer cognitive effects of both the disease and its therapies. Outcome assessment of patients with craniopharyngioma should ideally include this information to obtain a holistic picture.

\section{Conclusions}

We present a small but highly focused retrospective study on the efficacy of P32 instillation in pediatric patients with primarily cystic craniopharyngiomas who did not undergo concurrent EBR. Long-term cyst control was achieved in very few patients, and $77.7 \%$ of them required subsequent radiation therapy within $22.2 \pm 17.8$ months. Treatment of patients with craniopharyngiomas should be individualized with multimodal therapy; our data do not support brachytherapy as a stand-alone treatment for cysts.

\section{References}

1. Abayomi OK: Pathogenesis of irradiation-induced cognitive dysfunction. Acta Oncol 35:659-663, 1996

2. Albright AL, Hadjipanayis CG, Lunsford LD, Kondziolka D, Pollack IF, Adelson PD: Individualized treatment of pediatric craniopharyngiomas. Childs Nerv Syst 21:649-654, 2005

3. Backlund EO, Axelsson B, Bergstrand CG, Eriksson AL, Norén G, Ribbesjö E, et al: Treatment of craniopharyngiomas - the stereotactic approach in a ten to twenty-three years' perspective. I. Surgical, radiological and ophthalmological aspects. Acta Neurochir (Wien) 99:11-19, 1989

4. Barriger RB, Chang A, Lo SS, Timmerman RD, DesRosiers C, Boaz JC, et al: Phosphorus-32 therapy for cystic craniopharyngiomas. Radiother Oncol 98:207-212, 2011

5. Blackburn TP, Doughty D, Plowman PN: Stereotactic intracavitary therapy of recurrent cystic craniopharyngioma by instillation of 90yttrium. Br J Neurosurg 13:359-365, 1999

6. Fischer EG, Welch K, Shillito J Jr, Winston KR, Tarbell NJ: Craniopharyngiomas in children. Long-term effects of conservative surgical procedures combined with radiation therapy. J Neurosurg 73:534-540, 1990

7. Hasegawa T, Kondziolka D, Hadjipanayis CG, Lunsford LD: Management of cystic craniopharyngiomas with phosphorus-32 intracavitary irradiation. Neurosurgery 54:813-822, 2004

8. Haupt R, Magnani C, Pavanello M, Caruso S, Dama E, Garrè ML: Epidemiological aspects of craniopharyngioma. J Pediatr Endocrinol Metab 19 (Suppl 1):289-293, 2006

9. Hoffman HJ, De Silva M, Humphreys RP, Drake JM, Smith ML, Blaser SI: Aggressive surgical management of craniopharyngiomas in children. J Neurosurg 76:47-52, 1992

10. Honegger J, Buchfelder M, Fahlbusch R: Surgical treatment of craniopharyngiomas: endocrinological results. J Neurosurg 90:251-257, 1999

11. Julow J, Backlund EO, Lányi F, Hajda M, Bálint K, Nyáry $\mathrm{I}$, et al: Long-term results and late complications after intracavitary yttrium-90 colloid irradiation of recurrent cystic craniopharyngiomas. Neurosurgery 61:288-296, 2007

12. Julow JV: Intracystic irradiation for craniopharyngiomas. Pituitary 16:34-45, 2013

13. Kalapurakal JA: Radiation therapy in the management of pediatric craniopharyngiomas - a review. Childs Nerv Syst 21:808-816, 2005

14. Karavitaki N, Brufani C, Warner JT, Adams CB, Richards P, Ansorge O, et al: Craniopharyngiomas in children and adults: systematic analysis of 121 cases with long-term follow-up. Clin Endocrinol (Oxf) 62:397-409, 2005

15. Karavitaki N, Cudlip S, Adams CB, Wass JA: Craniopharyngiomas. Endocr Rev 27:371-397, 2006

16. Kawamata T, Amano K, Aihara Y, Kubo O, Hori T: Optimal treatment strategy for craniopharyngiomas based on longterm functional outcomes of recent and past treatment modalities. Neurosurg Rev 33:71-81, 2010

17. Kickingereder P, Maarouf M, El Majdoub F, Fuetsch M, Lehrke R, Wirths J, et al: Intracavitary brachytherapy using stereotactically applied phosphorus-32 colloid for treatment of cystic craniopharyngiomas in 53 patients. $\mathbf{J}$ Neurooncol 109:365-374, 2012

18. Kramer S, McKissock W, Concannon JP: Craniopharyngiomas. Treatment by combined surgery and radiation therapy. $\mathbf{J}$ Neurosurg 18:217-226, 1961

19. Leksell L, Liden K: A therapeutic trial with radioactive isotopes in cystic brain tumour. Radioisotopes techniques I. J Med Physiol Appl:1-4, 1952

20. Packer RJ, Zhou T, Holmes E, Vezina G, Gajjar A: Survival and secondary tumors in children with medulloblastoma receiving radiotherapy and adjuvant chemotherapy: results of Children's Oncology Group trial A9961. Neuro Oncol 15:97-103, 2013 
21. Pollack IF, Lunsford LD, Slamovits TL, Gumerman LW, Levine G, Robinson AG: Stereotaxic intracavitary irradiation for cystic craniopharyngiomas. J Neurosurg 68:227-233, 1988

22. Pollock BE, Lunsford LD, Kondziolka D, Levine G, Flickinger JC: Phosphorus-32 intracavitary irradiation of cystic craniopharyngiomas: current technique and long-term results. Int J Radiat Oncol Biol Phys 33:437-446, 1995

23. Schatz J, Kramer JH, Ablin A, Matthay KK: Processing speed, working memory, and IQ: a developmental model of cognitive deficits following cranial radiation therapy. Neuropsychology 14:189-200, 2000

24. Stafford SL, Pollock BE, Leavitt JA, Foote RL, Brown PD, Link MJ, et al: A study on the radiation tolerance of the optic nerves and chiasm after stereotactic radiosurgery. Int J Radiat Oncol Biol Phys 55:1177-1181, 2003

25. Stripp DC, Maity A, Janss AJ, Belasco JB, Tochner ZA, Goldwein JW, et al: Surgery with or without radiation therapy in the management of craniopharyngiomas in children and young adults. Int J Radiat Oncol Biol Phys 58:714-720, 2004

26. Takahashi H, Nakazawa S, Shimura T: Evaluation of postoperative intratumoral injection of bleomycin for craniopharyngioma in children. J Neurosurg 62:120-127, 1985

27. Van den Berge JH, Blaauw G, Breeman WA, Rahmy A, Wijngaarde R: Intracavitary brachytherapy of cystic craniopharyngiomas. J Neurosurg 77:545-550, 1992

28. Voges J, Sturm V, Lehrke R, Treuer H, Gauss C, Berthold F: Cystic craniopharyngioma: long-term results after intracavitary irradiation with stereotactically applied colloidal betaemitting radioactive sources. Neurosurgery 40:263-270, 1997
29. Wara WM, Sneed PK, Larson DA: The role of radiation therapy in the treatment of craniopharyngioma. Pediatr Neurosurg 21 (Suppl 1):98-100, 1994

30. Wen BC, Hussey DH, Staples J, Hitchon PW, Jani SK, Vigliotti AP, et al: A comparison of the roles of surgery and radiation therapy in the management of craniopharyngiomas. Int J Radiat Oncol Biol Phys 16:17-24, 1989

31. Yang I, Sughrue ME, Rutkowski MJ, Kaur R, Ivan ME, Aranda D, et al: Craniopharyngioma: a comparison of tumor control with various treatment strategies. Neurosurg Focus 28(4):E5, 2010

\section{Disclosures}

The authors report no conflict of interest concerning the materials or methods used in this study or the findings specified in this paper.

\section{Author Contributions}

Conception and design: all authors. Acquisition of data: all authors. Analysis and interpretation of data: all authors. Drafting the article: all authors. Critically revising the article: all authors. Reviewed submitted version of manuscript: all authors. Approved the final version of the manuscript on behalf of all authors: Fulkerson. Study supervision: Fulkerson.

\section{Correspondence}

Daniel H. Fulkerson, Goodman Campbell Brain and Spine, Riley Hospital for Children, 702 Barnhill Dr., \#1134, Indianapolis, IN 46202-5200. email: dfulkers@iupui.edu. 